\title{
A Retrospective Case Study of 13 Uterine Perivascular Epithelioid Cell Neoplasm (PEComa) Patients
}

This article was published in the following Dove Press journal: OncoTargets and Therapy

Jiahui Gu

Wantong Wang

Shizhuo Wang

Department of Obstetrics and Gynecology, Shengjing Hospital of China Medical University, Shenyang, Liaoning Province, II000I, People's Republic of China
Correspondence: Shizhuo Wang Department of Obstetrics and Gynecology, Shengjing Hospital of China Medical University, Sanhao Street No. 36, Heping District, Shenyang, Liaoning,

People's Republic of China

Tel +86 I8940257692

Email zhuol014@hotmail.com
Introduction and Hypothesis: Perivascular epithelioid cell neoplasms (PEComas) are rare mesenchymal tumors that originate from perivascular epithelioid cells. The uterus is the second most common organ to be affected by PEComa. Most PEComas are benign and the prognosis is usually good. Surgery is the main treatment at present, and adjuvant therapy is mainly used for malignant cases. However, because of the lack of described cases, the best diagnosis and treatment of these tumors cannot be determined.

Methods: From 2009 to 2020, 13 patients from Shengjing Hospital (China Medical University), with uterine PEComa, who met the inclusion criteria and appropriate pathological diagnosis were enrolled in this study. Clinical, pathological, and therapeutic features were retrospectively analyzed to determine the best approach towards diagnosis and treatment.

Results: All the enrolled patients underwent surgical treatment; four of them had a malignant PEComa. Three of the malignant patients received chemotherapy after surgery; among them, one died, another showed no obvious recurrence after regular re-examination, and the third did not undergo any further treatment despite short-term recurrence. However, upon regular re-examination, no progress was observed. The fourth malignant patient did not receive chemotherapy after surgery and showed no obvious recurrence during regular reviews.

Conclusion: The preoperative diagnosis of uterine PEComa lacks specificity and therefore is often confused with uterine leiomyoma or leiomyosarcoma. We conclude that uterine PEComa can be diagnosed by combined analysis of immunohistochemistry and postoperative pathology. Though surgical resection is still the main treatment, high-risk patients can be given adjuvant treatment to strengthen disease control.

Keywords: case study, pathology, perivascular epithelioid cell neoplasm, PEComa, treatment, uterus

\section{Introduction}

Perivascular epithelioid cell neoplasms (PEComas) are rare mesenchymal tumors and were first reported in 1991. The term "PEComa" was first proposed by Zamboni et al in $1996^{1}$ for tumors that originate from the perivascular epithelioid cells. PEComas refer to a family of mesenchymal neoplasms composed of angiomyolipomas, clear cell "sugar" tumors of the lung, and lymphangioleiomyomatoses. These tumors are usually rare and mostly benign, and when they occur, the uterus is the second most common lesion site to be affected, after the 
retroperitoneum. ${ }^{2}$ Until now, approximately 100 PEComa cases have been reported, of which one-third of these affected the uterus. Due to the lack of reported PEComa cases, no uniform standards of diagnosis and treatment have been established, either in China or abroad.

Folpe et al recently proposed PEComa grading criteria. ${ }^{3}$ Based on these criteria, PEComa is classified into three categories: ${ }^{3,4}$ benign, uncertain malignant potential, and malignant. Because of the rare occurrence of this disease, any atypical nuclear features, if not indicated by suspicious histology, should be considered "potentially malignant," even if benign during diagnosis. Uterine PEComa has no specific morphological characteristics but can show stromal hyalinization and vascularization.

The normal tissue counterparts of PEComas are unclear, but they have immunohistochemical (IHC) responses to both melanocytes and myeloid markers. ${ }^{5}$ Folpe et $\mathrm{al}^{3}$ reviewed 26 cases of PEComas of both soft tissue and gynecologic origin. According to their report, at least one of the melanocytic markers (Human Melanoma Black [HMB-45], Melan-A, and microphthalmia transcription factor) was expressed in all PEComa cases, with HMB-45 showing the highest positive expression rate in $92 \%$ of cases. PEComas also showed positive expression for the myeloid marker smooth muscle actin (SMA; 80\%) and desmin (36\%).

The incidence of PEComas has also been reported to be associated to a certain extent (9\%) with tuberous sclerosis (TSC). ${ }^{3,6,7}$

In this study, we retrospectively investigated 13 PEComa patients who were admitted to our hospital within the past 12 years, analyzing their clinical features, pathogenesis, and treatment strategies to improve the existing knowledge and approach towards PEComas.

\section{Patients and Methods}

The procedures of the current study were conducted in accordance with the World Medical Association Declaration of Helsinki-Ethical Principles for Medical Research involving Human Subjects. This study was approved by the Responsible Committee on Human Experimentation of China Medical University. Written informed consent was obtained from each participant before data collection. Between 2009 and 2020, 13 patients pathologically confirmed with uterine PEComa were enrolled in this study. The patients were treated in the Department of Gynecology in Shengjing Hospital at China Medical University. All the clinical data of the patients were retrospectively analyzed (including admission, examination, surgery, pathology reports, treatment, and follow-up records).

The ages of the patients ranged between 34 and 56 years, and there were no other complications found during the preoperative examination. All patients underwent surgical treatment, thereby enabling postoperative pathology and immunohistochemistry of PEComas. Four of the 13 patients were diagnosed with malignant PEComa.

\section{Results \\ Clinical Features Classification}

As per the grading criteria, the 13 PEComa cases were graded as benign (3), uncertain malignant potential (6), and malignant (4).

\section{Epidemiology}

Although the ages of the patients ranged between 34 and 56 years, all patients except for one 34-year-old were aged between 44 and 56 years. This age range coincided with a high-onset period perimenopause.

All patients were treated surgically, which led to the diagnosis of PEComa after examining their postoperative pathology and IHC results. Pathological results of four patients were malignant, among which, three received postoperative chemotherapy and the fourth did not receive any adjuvant treatment. No other medical history was reported in this study.

\section{Clinical Manifestations}

Precise diagnosis of gynecological PEComa is difficult due to lack of specific clinical manifestations. Most symptoms occur in the uterine body without involving the cervix. ${ }^{8-10}$ Statistical analysis suggests that the occurrence of PEComa clinical symptoms was not specific; ten cases in the uterine body, one in the cervix, one in the vaginal end, and one in the pelvic and abdominal lymph nodes (Table 1).

Clinical manifestations of PEComa vary with tumor size, location, and spread. Usually small, asymptomatic tumors are found during physical examination. Common symptoms include altered menstruation, irregular vaginal bleeding, and abdominal pain observed in $23.1 \%, 30.8 \%$, and $15.4 \%$ of PEComa cases, respectively. Physical examination was also observed in $30.8 \%$ of cases.

Pelvic ultrasound was performed preoperatively in all nine benign patients, including five with uterine fibroids 
Table I Site of Occurrence Observed in PEComa Patients

\begin{tabular}{|l|c|c|}
\hline Site of Occurrence & $\begin{array}{c}\text { Number of } \\
\text { Cases }\end{array}$ & Percentage \\
\hline Uterine body & 10 & $76.9 \%$ \\
\hline Cervix & I & $7.69 \%$ \\
\hline Vaginal end & I & $7.69 \%$ \\
\hline $\begin{array}{l}\text { Pelvic and abdominal lymph } \\
\text { nodes }\end{array}$ & I & $7.69 \%$ \\
\hline
\end{tabular}

(55.6\%), and four with no definite diagnosis, indicating uterine space occupation and accessory area or uterine wall mass.

\section{Pathology \\ Morphological Characteristics}

Most of the morphological features of uterine PEComas are similar to those of PEComas affecting other anatomical parts. Perivascular epithelioid cells usually grow in lamellar or nested shapes and are often closely related to significant vascular components. This perivascular distribution is a unique characteristic and led to preliminary speculation that it might come from the vessel wall.

Gynecological PEComas showed different amounts of matrix hyaluronic acid. In some cases, the degree of transparency is so great that the epithelioid cells appear to be immersed in a hyaline background. ${ }^{11-13}$ Uterine PEComas can be well- or partially wrapped, or can diffusely infiltrate the uterine muscle. ${ }^{8,11}$ The vascularization of PEComas usually exhibits characteristic features, usually consisting of a network of small blood vessels throughout the tumor. ${ }^{11}$

Of the 13 cases, eight of the histopathologic sections showed patchy or nested arrangement of cells with thickwalled vessels $(61.5 \%)$.

\section{Immunohistochemical Features}

Immunohistochemical analysis of the 13 cases enrolled in this study revealed markers indicated in Table 2. Patient tissues were observed to positively stain for both melanocytic and myeloid molecular markers such as HMB-45 (82\%), SMA (82\%), Melan-A (50\%), vimentin (36\%), desmin (29\%), CD10 (25\%), and CD34 (25\%), while IHC markers like CD117, S100, inhibin, and cytokeratin were completely absent. Ki-67 positive staining was observed in all 13 cases (Table 2).
Table 2 Results of Immunohistochemical Analysis Performed on PEComa Patients

\begin{tabular}{|l|c|}
\hline Immunohistochemical Marker & Positive Rate \\
\hline HMB45, SMA & $82 \%$ \\
\hline Melan-A & $50 \%$ \\
\hline Vimentin & $36 \%$ \\
\hline Desmin & $29 \%$ \\
\hline CDI0, CD34, CDII7 & $25 \%$ \\
\hline SI00, inhibin, CK & $0 \%$ \\
\hline
\end{tabular}

\section{Differential Diagnosis}

Because of an overlap in morphological features and age group incidence, it is difficult to distinguish PEComa from uterine fibroids before surgery. If coagulation necrosis and/ or $>10$ high-power fields are present, both pathologies can be considered malignant. ${ }^{14}$ In addition, although keratin is positively expressed in both, it is more common in uterine fibroids, ${ }^{15,16}$ while desmin is present in about $50 \%$ of both uterine fibroids and PEComas. ${ }^{15,17}$

It has been observed that PEComas have a fine vascular network indicated by IHC markers, while uterine fibroids do not. Therefore, it is possible to separate the uterine PEComas and uterine fibroids morphologically based on this feature. ${ }^{18}$ However, further case accumulation, comparisons, and research are required to confirm this more efficiently. At present, the differentiation between uterine PEComas and uterine fibroids is mainly dependent on postoperative pathology and immunohistochemistry.

\section{Treatment}

No specific clinical guidelines have been established for the treatment of uterine PEComas due to lack of sufficient cases. Surgery is still the main treatment, for malignant and high-risk cases, after which a corresponding chemotherapy and radiotherapy are normally given. However, there is no unified treatment plan, and the outcomes of therapy among our patients were mixed.

\section{Surgery}

Among the 13 cases enrolled in this study, total hysterectomy was performed in seven, comprising bilateral adnexectomy in postmenopausal patients, and tumor resection in two others, retaining their fertility. Postoperative 
Table 3 Surgical Treatment Plan Provided for PEComa Patients

\begin{tabular}{|l|c|}
\hline $\begin{array}{l}\text { Pathology of } \\
\text { Benign }\end{array}$ & Surgery \\
\hline 3 patients & Total hysterectomy \\
\hline 4 patients & $\begin{array}{r}\text { Total hysterectomy and bilateral } \\
\text { adnexectomy }\end{array}$ \\
\hline 2 patients & $\begin{array}{c}\text { Tumor resection, fertility preserving } \\
\text { function }\end{array}$ \\
\hline
\end{tabular}

pathology indicated the presence of benign tumors in all nine surgical cases (Table 3).

\section{Chemotherapy for Metastatic Disease}

Out of 13 cases enrolled in this study, four were malignant. Of the malignant cases, three received postoperative chemotherapy, and one received no adjuvant therapy.

One case diagnosed with "peritoneal disseminated leiomyoma disease" received a total hysterectomy, bilateral adnexectomy, pelvic neoplasm and pelvic lymph node resection. The postoperative pathology was considered to be "malignant potential in leiomyoma." Four years later, the patient had vaginal cuff lesions and received a pelvic neoplasm resection, while postoperatively considered to have "PEComa of vaginal cuff end." According to literature reports, she received PIA scheme (cisplatin + ifosfamide + doxorubicin hydrochloride liposome) chemotherapy four times. However, chemotherapy was inefficient, as the patient showed vaginal cuff neoplasm recurrence during a 4-month review. No further treatment was provided, and the patient is still alive and has regular re-examination every six months.

With respect to the second case, hysterectomy was performed for "uterine fibroids" diagnosed initially. One year later, cervical resection and bilateral adnexectomy were performed for a cervical mass. However, pelvic lymph node resection was not performed for pelvic adhesion and closure. The postoperative pathology was diagnosed as "cervical malignant PEComa" with no adjuvant therapy after the operation. Recurrence was observed three months later and in spite of chemotherapy (cisplatin + ifosfamide + epirubicin) administered once every 3 weeks, 3 times in total (the choice of chemotherapy regimen was based on literature reports), the treatment effectiveness was poor. Systemic metastasis was observed, accompanied by organ failure, and finally death.
Total hysterectomy and bilateral adnexectomy were performed on the third case for intramural uterine nodules and was postoperatively diagnosed with "malignant uterine PEComa." Chemotherapy with cisplatin + doxorubicin + ifosfamide was administered once every 3 weeks, 4 times in total (according to literature reports). There were no signs of relapse or metastasis, and the patient is still alive.

For the last case initially diagnosed with "endometrial adenocarcinoma," total extra-fascial hysterectomy, bilateral adnexectomy, and pelvic and para-aortic lymph node resection were performed. Postoperative pathological examination revealed "pelvic and para-aortic lymph node PEComa." No adjuvant treatment such as chemoradiotherapy was administered after the operation. The patient is still alive and regular reviews indicated no obvious signs of relapse and metastasis.

\section{Radiation Therapy}

None of the four malignant cases in this study received radiation therapy.

\section{Survival and Recurrence}

Nine patients with benign PEComa underwent regular reexaminations at two, four, five, six, and ten years after surgery, and no signs of recurrence were found.

The patient with "PEComa of vaginal cuff end" did not receive any treatment after recurrence, and the tumor was re-examined every six months. The tumor showed no significant changes and did not deteriorate until two years later.

The patient with "cervical malignant PEComa" was admitted to the ICU due to critical illness after one month of chemotherapy, and later died.

The patient with "malignant uterine PEComa" underwent regular re-examinations after chemotherapy and showed no signs of recurrence or metastasis even after five years.

The patient with "pelvic and para-aortic lymph node PEComa" did not receive radiotherapy or chemotherapy after surgery, and no obvious signs of relapse or metastasis were observed during regular review until relapse occurred seven years later.

\section{Discussion}

Currently, not more than 100 cases of gynecological PEComa have been reported. Usually, PEComa patients range from young girls to elderly patients, with peak incidence at approximately the age of $40 .^{14}$ 
Though no special medical history has been reported in this study, other reports have indicated that $9 \%$ of PEComas are associated with TSC. ${ }^{3,6,7}$ This association is possibly due to the genetic mutations caused by TSC1 or TSC2 gene inactivation as well as high aggressiveness of TSC. $^{14}$

Clinical manifestations, pelvic ultrasound, and radiological examination lack specificity, and can indicate either benign smooth tumors similar to uterine fibroids, or heterogeneous masses with malignancy. ${ }^{19-21}$ The lack of specific clinical and radiological manifestations has not only made the diagnosis and treatment of PEComa difficult but also delayed the opportunity for treatment in some cases.

PEComas express the myeloid melanocyte phenotype and are immunoreactive to both melanocytes and smooth muscle markers. The immunoreactivity of HMB-45, and other melanocyte markers, has been extensively demonstrated. $^{22-26}$ The most relevant of these markers are microphthalmia transcription factor, Melan-A/Mart-1, and HMSA- $1 .{ }^{27}$ In some cases, immune responses to the smooth muscle marker, SMA, are present, and lower immunopositivity rates have been shown for vimentin and/or desmin. ${ }^{6,11,28}$ Cathepsin $\mathrm{K}$ expression is another reportedly useful marker for diagnosing PEComas. ${ }^{29}$ Additionally, the expression of HMB-45 is reported to be always positive in PEComas, while the positive rate of Melan-A is $80 \%$, and that of S100 and cytokeratins is always negative. ${ }^{13,26,30-40}$ Considering the anatomical distribution, morphology, and IHC characteristics of PEComa observed in this study and other reports, and the lack of normal counterparts, completely understanding PEComa tissue development is complicated. Further investigations are required to arrive at a proper understanding of PEComa histogenesis, in order to provide guidance for the study of the pathogenesis and treatment of uterine PEComa.

Despite the different combinations of cisplatin, ifosfamide, epirubicin, and doxorubicin treatment given to PEComa patients in this study, a definite conclusion cannot be reached with respect to therapeutic efficacy. It is notable that malignant patients also have a good chance of survival without any adjuvant therapy. Due to limited reported cases, the optimal chemotherapy regimen for gynecological malignant PEComa is still uncertain, and more exploratory studies are required in the future.

At present, the role of radiotherapy is not clear. Histology of malignant PEComa reportedly shows high mitotic index and multiple necrosis. ${ }^{14}$ Although necrosis is related to radiation tolerance, high mitotic index and abundant angiogenesis (a typical feature of PEComa tumors) are related to high sensitivity of cells to radiation. ${ }^{14}$ This supports the use of radiotherapy as a reasonable treatment for patients with malignant PEComa.

PEComas are usually localized, ${ }^{32}$ but distal metastasis is most commonly found in the lung. ${ }^{39,41}$ Duration of the distant metastasis shows considerable variation, ranging from one month to 15 years. ${ }^{3,13,36-40}$ For metastatic spread, there is no clear treatment reported in the literature.

Systemic chemotherapy regimens are not very effective, leaving surgery as the best treatment option. Therefore, postoperative adjuvant chemotherapy does not play a decisive role in the prognosis of patients with malignant PEComa, as surgery is still the main treatment. Most malignant PEComas have good survival without recurrence or metastasis for several years. ${ }^{5}$

Certain studies have reported that mammalian target of rapamycin (mTOR) inhibitor-targeted therapy has achieved remarkable results in patients with malignant PEComas. ${ }^{42-44}$ In addition, IHC and biochemical analyses have shown inactivation of TSC $1 / 2$ and excessive activation of the mTOR pathway in non-TSC tumors. ${ }^{3,11}$ Based on these reports, mTOR inhibitors certainly deserve further probing for the treatment of gynecologic PEComas.

Several questions about these rare tumors remain unclear. Although the best treatment for PEComas has not yet been determined, surgical resection is still the preferred treatment. According to the literature, most PEComa patients have undergone total hysterectomy and bilateral salpingo- oophorectomy depending upon their age. ${ }^{11}$ Nine patients in this study with tumors considered "benign" showed no recurrence even after ten years after surgery.

While simple surgical treatment may seem appropriate for patients with both undetermined benign and malignant PEComas, postoperative adjuvant therapy must be given to patients with malignant PEComas in spite of the poor efficacy of radiotherapy and chemotherapy. Jeon et $\mathrm{al}^{33}$ reported that the combination of chemotherapy and radiotherapy after malignant PEComa surgery performed well, with disease-free survival for 18 months. Similarly, other studies reported six, 36, and 24 months of disease-free survival after surgery. ${ }^{3,18,45}$ Ong et al $^{18}$ reported six months of disease-free survival after surgery, Folpe et $\mathrm{al}^{3}$ reported that 26 soft-tissue and gynecological PEComa patients had 36 months of disease-free survival after surgery, and Vang and Kempson reported disease-free 
survival cases two years after surgery. ${ }^{45}$ Of the four malignant patients in this study, two survived disease-free for five and seven years, and one patient received no adjuvant therapy after surgery. However, due to the lack of sufficient reports and randomized trials, and diverse treatment strategies used, there is no optimal or uniform treatment regimen for this disease.

For targeted therapy, the goal of treatment is to reduce recurrence and metastasis, which is important for better prognosis. More recently, mTOR inhibitors have been reported to achieve significant progress with respect to malignant PEComa treatment. ${ }^{42}$ Therefore, mTOR inhibitors can be temporarily used as an effective alternative for metastatic PEComa, even though further clinical practice and research are still required to define the best therapeutic regimen.

Uterine PEComa is a rare disease and is mainly diagnosed after examining its postoperative pathology and immunohistochemistry. It has varying prognosis based on its benign and malignant features. Although the treatment guidelines for PEComas are not uniform, and the best treatment plan is undetermined, surgical resection is still considered to be the basic and the first choice of treatment to date. For malignant patients, postoperative adjuvant therapy is still considered necessary to reduce the recurrence as well as the metastatic rate of this disease while improving the survival rate.

Through data collection, this article counts some clinical cases of uterine PEComa, and summarizes the characteristics of the disease from its clinical manifestations, imaging examinations, pathology, treatment, and prognosis. The information provided may be helpful to the disease. At the same time, it can be used as a valuable reference material for teaching hospitals on the disease. However, because uterine PEComa is relatively rare, the data currently available is limited, and it is difficult to follow up patients earlier, which is the limitation of this study. Further research, the future improvement of diagnosis and treatment through multidisciplinary methods is worth exploring.

\section{Brief Summary}

Uterine perivascular epithelioid cell neoplasm (PEComa) cases are rare. In this paper, 13 cases of benign and malignant uterine PEComas were retrospectively analyzed to facilitate the further study of this disease.

\section{Data Sharing Statement}

The datasets used and/or analyzed during the current study are available from the corresponding author on request.

\section{Ethics Approval and Consent to Participate}

Ethics approval was granted by the Shengjing Hospital Ethics Committee. The cases' details were obtained and consented to publish from the patients and their families.

\section{Author Contributions}

All authors contributed to data analysis, drafting or revising the article, have agreed on the journal to which the article will be submitted, gave final approval of the version to be published, and agree to be accountable for all aspects of the work.

\section{Funding}

There is no funding to report.

\section{Disclosure}

The authors report no conflicts of interest in this work.

\section{References}

1. Pea M, Bonetti F, Zamboni G, et al. Melanocyte-marker-HMB-45 is regularly expressed in angiomyolipoma of the kidney. Pathology. 1991;23(3):185-188. doi:10.3109/00313029109063563

2. Pea M, Bonetti F, Zamboni G, Martignoni G, Fiore-Donati L, Doglioni C. Clear cell tumor and angiomyolipoma. Am J Surg Pathol. 1991;15(2):199-200. doi:10.1097/00000478-19910200000020

3. Folpe AL, Mentzel T, Lehr HA, Fisher C, Balzer BL, Weiss SW. Perivascular epithelioid cell neoplasms of soft tissue and gynecologic origin: a clinicopathologic study of 26 cases and review of the literature. Am J Surg Pathol. 2005;29(12):1558-1575. doi:10.1097/ 01.pas.0000173232.22117.37

4. Folpe AL, Kwiatkowski DJ. Perivascular epithelioid cell neoplasms: pathology and pathogenesis. Hum Pathol. 2010;41(1):1-5. doi:10.1016/j.humpath.2009.05.011

5. Fletcher CDM, Bridge JA, Hogendoorn P, Mertens F. WHO Classification of Tumors of Soft Tissue and Bone. Fourth ed. IARC Press: Lyon; 2013.

6. Fang CL, Lin YH, Chen WY. Microscopic endometrial perivascular epithelioid cell nodules: a case report with the earliest presentation of a uterine perivascular epithelioid cell tumor. Diagn Pathol. 2012;7 (1):117. doi:10.1186/1746-1596-7-117

7. Yamada $\mathrm{Y}$, Yamamoto $\mathrm{H}$, Ohishi $\mathrm{Y}$, et al. Sclerosing variant of perivascular epithelioid cell tumor in the female genital organs. Pathol Int. 2011;61(12):768-772. doi:10.1111/j.14401827.2011.02737.x

8. Fadare O. Uterine PEComa: appraisal of a controversial and increasingly reported mesenchymal neoplasm. Int Semin Surg Oncol. 2008;5 (1):7. doi:10.1186/1477-7800-5-7

9. Stone JL, Batty T, Nicklin J. Cervical perivascular epithelioid cell tumor (PEComa) of the uterine cervix: cytological findings in a cervical smear. Cytopathology. 2013;24(4):272-273. doi:10.1111/ j.1365-2303.2012.00989.x

10. Azad NS, Pervez S, Kayani N, Aziz AB. Uterine perivascular epithelioid cell tumor presenting as a cervical mass. J Pak Med Assoc. 2006;56(2):83.

11. Fadare O. Perivascular epithelioid cell tumor (PEComa) of the uterus: an outcome-based clinicopathologic analysis of 41 reported cases. $A d v$ Anat Pathol. 2008;15(2):63-75. doi:10.1097/PAP.0b013e31816613b0 
12. Hornick JL, Fletcher CD. PEComa: what do we know so far? Histopathology. 2006;48(1):75-82. doi:10.1111/j.13652559.2005.02316.x

13. Fukunaga M. Perivascular epithelioid cell tumor of the uterus: report of four cases. Int $J$ Gynecol Pathol. 2005;24(4):341-346. doi:10.1097/01.pgp.0000168515.83557.89

14. Musella A, De Felice F, Kyriacou AK, et al. Perivascular epithelioid cell neoplasm (PEComa) of the uterus: a systematic review. Int J Surg. 2015;1(19):1-5. doi:10.1016/j.ijsu.2015.05.002

15. Pea M, Martignoni G, Zamboni G, Bonetti F. Perivascular epithelioid cell. Am J Surg Pathol. 1996;20(9):1149-1153. doi:10.1097/ 00000478-199609000-00012

16. Tanaka Y, Ijiri R, Kato K, et al. HMB-45/melan-A and smooth muscle actin-positive clear-cell epithelioid tumor arising in the ligamentum teres hepatis: additional example of clear cell 'sugar' tumors. Am J Surg Pathol. 2000;24(9):1295-1299. doi:10.1097/ 00000478-200009000-00015

17. Michal M, Zamecnikt M. Hyalinized uterine mesenchymal neoplasms with HMB-45-positive epithelioid cells: epithelioid leiomyomas or angiomyolipomas? Report of four cases. Int J Surg Pathol. 2000;8(4):323-328. doi:10.1177/106689690000800411

18. Ong LY, Hwang WS, Wong A, Chan MY, Chui CH. Perivascular epithelioid cell tumor of the vagina in an 8 year old girl. $J$ Pediatr Surg. 2007;42(3):564-566. doi:10.1016/j.jpedsurg.2006.10.050

19. Prasad SR, Sahani DV, Mino-Kenudson M, et al. Neoplasms of the perivascular epithelioid cell involving the abdomen and the pelvis: cross-sectional imaging findings. J Comput Assist Tomogr. 2007;31 (5):688-696. doi:10.1097/rct.0b013e318031912f

20. Giannella L, Carpini GD, Montik N, et al. Ultrasound features of a uterine perivascular epithelioid cell tumor (PEComa): case report and literature review. Diagnostics. 2020;10(8):553. doi:10.3390/ diagnostics 10080553

21. Pattamapaspong N, Khunamornpong S, Phongnarisorn C, Pojchamarnwiputh S. Malignant perivascular epithelioid cell tumor of the round ligament mimics leiomyoma on computed tomography. Singapore Med J. 2009;50(7):e239-e242.

22. Ye HY, Chen JG, Luo DL, Jiang ZM, Chen ZH. Perivascular epithelioid cell tumor (PEComa) of gynecologic origin: a clinicopathological study of three cases. Eur J Gynaecol Oncol. 2012;33(1):105.

23. D'Angelo E, Prat J. Diagnostic use of immunohistochemistry in uterine mesenchymal tumors. Semin Diagn Pathol. 2014;31 (3):216-222. doi:10.1053/j.semdp.2014.03.003

24. Okada H, Terado Y, Fujiwara M, Mochizuki M, Ishizawa M, Kamma H. Perivascular epithelioid cell tumor of the uterus. Pathol Int. 2014;64(3):151-153. doi:10.1111/pin.12137

25. Sharma S, Kotru M, Gupta R. PEComata: highly melanotic multiple perivascular epithelioid cell tumors (PEComa) of the uterus. APMIS. 2008;116(11):1000-1003. doi:10.1111/j.1600-0463.2008.01034.x

26. Bosincu L, Rocca PC, Martignoni G, et al. Perivascular epithelioid cell (PEC) tumors of the uterus: a clinicopathologic study of two cases with aggressive features. Mod Pathol. 2005;18(10):1336. doi:10.1038/modpathol.3800433

27. Schoolmeester JK, Howitt BE, Hirsch MS, Dal Cin P, Quade BJ, Nucci MR. Perivascular epithelioid cell neoplasm (PEComa) of the gynecologic tract: clinicopathologic and immunohistochemical characterization of 16 cases. Am J Surg Pathol. 2014;38(2):176-188. doi:10.1097/PAS.0000000000000133

28. Park SH, Ro JY, Kim HS, Lee ES. Perivascular epithelioid cell tumor of the uterus: immunohistochemical, ultrastructural and molecular study. Pathol Int. 2003;53(11):800-805. doi:10.1046/j.14401827.2003.01557.x

29. Rao Q, Cheng L, Xia QY, et al. Cathepsin K expression in a wide spectrum of perivascular epithelioid cell neoplasms (PEComas): a clinicopathological study emphasizing extrarenal PEComas. Histopathology. 2013;62(4):642-650. doi:10.1111/his.12059
30. Ruco LP, Pilozzi E, Wedard BM, et al. Epithelioid lymphangioleiomyomatosis-like tumor of the uterus in a patient without tuberous sclerosis: a lesion mimicking epithelioid leiomyosarcoma. Histopathology. 1998;33(1):91-93. doi:10.1046/j.13652559.1998.0415g.x

31. Bonetti F, Martignoni G, Colato C, et al. Abdominopelvic sarcoma of perivascular epithelioid cells: report of four cases in young women, one with tuberous sclerosis. Mod Pathol. 2001;14(6):563-568. doi:10.1038/modpathol.3880351

32. Greene LA, Mount SL, Schned AR, Cooper K. Recurrent perivascular epithelioid cell tumor of the uterus (PEComa): an immunohistochemical study and review of the literature. Gynecol Oncol. 2003;90 (3):677-681. doi:10.1016/S0090-8258(03)00325-1

33. Jeon IS, Lee SM. Multimodal treatment using surgery, radiotherapy, and chemotherapy in a patient with a perivascular epithelioid cell tumor of the uterus. J Pediatr Hematol Oncol. 2005;27(12):681-684. doi:10.1097/01.mph.0000193475.06870.d5

34. Bleeker JS, Quevedo JF, Folpe AL. Malignant perivascular epithelioid cell tumor of the uterus. Rare Tumors. 2012;4(1):45-48. doi:10.4081/rt.2012.e14

35. Liu JL, Lin YM, Lin MC, Yeh KT, Hsu JC, Chin CJ. Perivascular epithelioid cell tumor (PEComa) of the uterus with aggressive behavior at presentation. Hematol Oncol Stem Cell Ther. 2009;2 (3):426-430. doi:10.1016/S1658-3876(09)50013-1

36. Dimmler A, Seitz G, Hohenberger W, Kirchner T, Faller G. Late pulmonary metastasis in uterine PEComa. J Clin Pathol. 2003;56 (8):627-628. doi:10.1136/jcp.56.8.627

37. Armah HB, Parwani AV. Malignant perivascular epithelioid cell tumor (PEComa) of the uterus with late renal and pulmonary metastases: a case report with review of the literature. Diagn Pathol. 2007;2(1):45. doi:10.1186/1746-1596-2-45

38. Yamashita K, Fletcher CD. PEComa presenting in bone: clinicopathologic analysis of 6 cases and literature review. Am J Surg Pathol. 2010;34(11):1622-1629. doi:10.1097/ PAS.0b013e3181f5974f

39. Cossu A, Paliogiannis P, Tanda F, Dessole S, Palmieri G, Capobianco G. Uterine perivascular epithelioid cell neoplasms (PEComas): report of two cases and literature review. Eur J Gynaecol Oncol. 2014;35(3):309-312.

40. Kang JB, Seo JW, Park YH, Jang PR. Malignant perivascular epithelioid cell tumor of the uterus with lung metastasis. Korean J Pathol. 2014;48(6):454-457. doi:10.4132/KoreanJPathol.2014.48.6.454

41. Gennatas C, Michalaki V, Kairi PV, Kondi-Paphiti A, Voros D. Successful treatment with the mTOR inhibitor everolimus in a patient with perivascular epithelioid cell tumor. World J Surg Oncol. 2012;10(1):181. doi:10.1186/1477-7819-10-181

42. Italiano A, Delcambre C, Hostein I, et al. Treatment with the mTOR inhibitor temsirolimus in patients with malignant PEComa. Ann Oncol. 2010;21(5):1135-1137. doi:10.1093/annonc/mdq044

43. Wagner AJ, Malinowska-Kolodziej I, Morgan JA, et al. Clinical activity of mTOR inhibition with sirolimus in malignant perivascular epithelioid cell tumors: targeting the pathogenic activation of mTORC1 in tumors. $J$ Clin Oncol. 2010;28(5):835-840. doi:10.1200/JCO.2009.25.2981

44. Dickson MA, Schwartz GK, Antonescu CR, Kwiatkowski DJ, Malinowska IA. Extrarenal perivascular epithelioid cell tumors (PEComas) respond to mTOR inhibition: clinical and molecular correlates. Int $J$ Cancer. 2013;132(7):1711-1717. doi:10.1002/ ijc. 27800

45. Vang R, Kempson RL. Perivascular epithelioid cell tumor (PEComa') of the uterus: a subset of HMB-45-positive epithelioid mesenchymal neoplasms with an uncertain relationship to pure smooth muscle tumors. Am J Surg Pathol. 2002;26(1):1-3. doi:10.1097/00000478200201000-00001 


\section{Publish your work in this journal}

OncoTargets and Therapy is an international, peer-reviewed, open access journal focusing on the pathological basis of all cancers, potential targets for therapy and treatment protocols employed to improve the management of cancer patients. The journal also focuses on the impact of management programs and new therapeutic agents and protocols on patient perspectives such as quality of life, adherence and satisfaction. The manuscript management system is completely online and includes a very quick and fair peer-review system, which is all easy to use. Visit http://www.dovepress.com/ testimonials.php to read real quotes from published authors. 